\title{
Synthetic Double-Stranded Helical Polymers
}
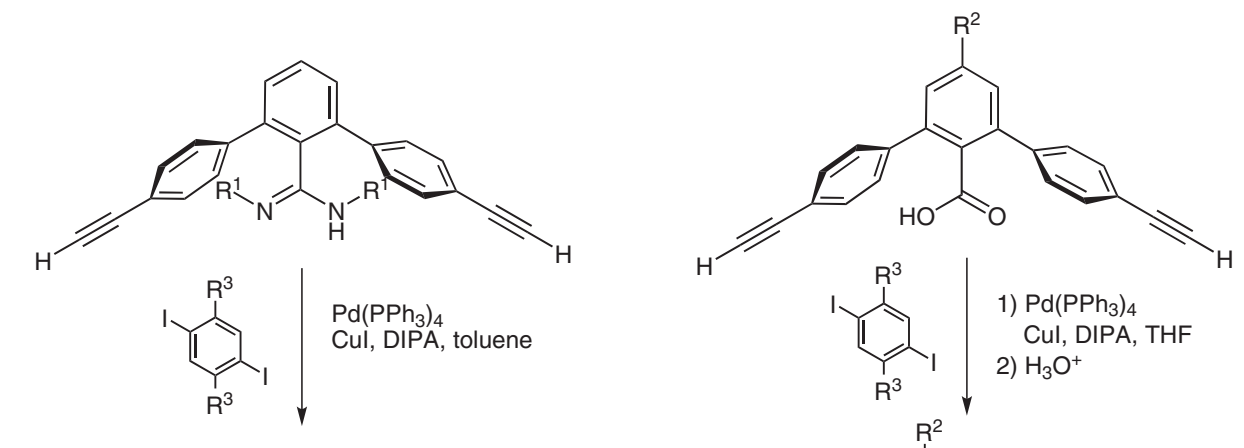

\section{Key words}

double helical polymers

hetero-strand

salt bridge
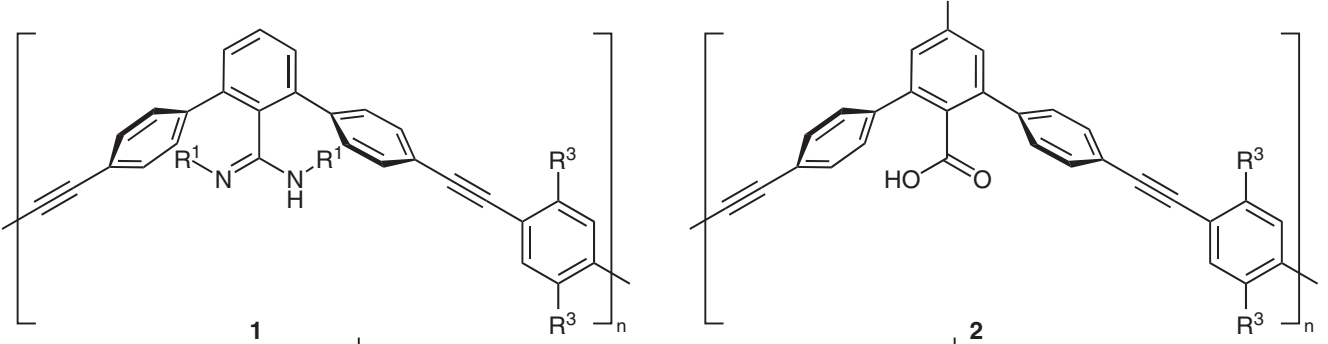

\section{SYNFACTuth}

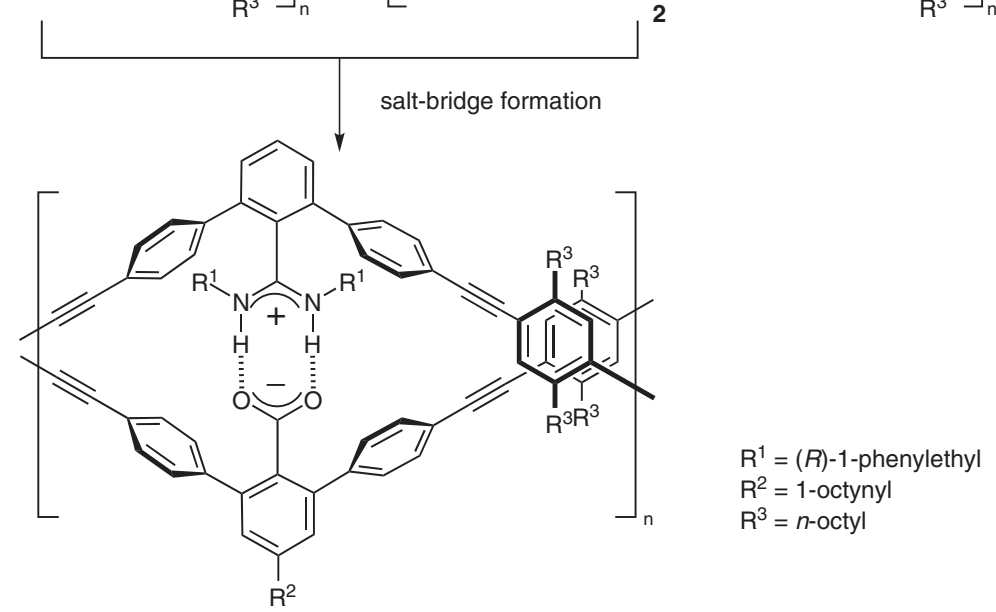

Significance: Reported is the first synthetic hetero-strand double helical polymer. Two complementary homopolymers $\mathbf{1}$ and $\mathbf{2}$ assembled into a perfect double helix via an interstrand amidiniumcarboxylate salt bridge in a polar solvent such as THF. The structure was verified by UV-Vis, CD, FT$\mathrm{IR}, \mathrm{AFM}$ and WAXD.
Comment: The authors reported a useful design rationale for the assembly of a multiple-component polymeric system. The helical structure may lead to new opportunities to materials research, such as enantioselective polymeric catalysis ( $A n$ gew. Chem. Int. Ed. 2007, 46, 5885), facilitated energy-transfer processes, and improved mechanical strength. 